\title{
Seek Forgiveness: Pemaafan pada Pemeluk Agama Islam dan Agama Kristen
}

\author{
Ika Herani ${ }^{1}$, Dianita Rachmawati ${ }^{1}$ \\ 1Jurusan Psikologi Universitas Brawijaya
}

DOI: http://doi.org/10.29080/jpp.v\%vi\%i.226

\begin{abstract}
Forgiveness is a change of individual motivation, from avoidance and revenge to conciliation. This study aims to compare forgiveness motivation between Moslem and Christian college students. Having quantitative designs with comparative analysis techniques, this study involved 1,497 college students in Indonesia with non-probability technique sampling. T-test was used in data analysis comparing two groups of samples. This study used Transgression-Related Interpersonal Motivation-12 (TRIM-12) as an instrument which was developed by McCullough (1998). The results indicated that there was no difference in the motivation of forgiveness between students who are Moslem and Christian.
\end{abstract}

Keywords : Forgiveness, Motivation, Moslem, Christian

\begin{abstract}
Abstrak: Pemaafan merupakan perubahan motivasi pada individu, dari penghindaran serta balas dendam menuju konsiliasi. Penelitian ini bertujuan untuk mengetahui perbedaan motivasi pemaafan antara mahasiswa pemeluk agama Islam dan agama Kristen. Menggunakan rancangan kuantitatif dengan teknik analisis komparatif, penelitian ini melibatkan 1.497 mahasiswa dengan teknik sample non-probability sampling. Teknik analisis yang digunakan adalah uji T-test untuk membandingkan dua kelompok sampel. Instrumen dalam penelitian ini menggunakan Transgression-Related Interpersonal Motivation-12 (TRIM-12) milik McCullough (1998). Hasil penelitian ini menunjukkan bahwa tidak terdapat perbedaan motivasi pemaafan antara mahasiswa yang beragama Islam dan mahasiswa beragama Kristen.
\end{abstract}

Kata kunci : Pemaafan, Motivasi, Islam, Kristen

\section{Pendahuluan}

Indonesia mengakui adanya enam agama yang dianut oleh warga negaranya yaitu Islam, Katholik, Kristen, Hindu, Budha, dan Konghucu. Adapun jumlah penganut agama tersebut adalah $87,18 \%$ penduduk beragama Islam, 6,96\% penduduk memeluk agama Kristen, 2,91\% beragama Katolik, 1,69\% beragama Hindu, 0,72\% beragama Budha, dan

Corresponding Author: Ika Herani (e-mail: herani@ub.ac.id) Jurusan Psikologi Universitas Brawijaya, Malang, Jawa Timur, Indonesia 
0,05\% beragama Konghucu (Badan Pusat Statistik Jakarta Pusat, 2010). Hal ini menunjukkan Indonesia sebagai salah satu negara pluralisme yang kaya akan keberagaman khususnya dalam hal agama. Keragaman agama di Indonesia tidak hanya menjadi potret pluralisme tetapi juga menjadi panutan toleransi dalam beragama di seluruh dunia. Agama seharusnya menjadi tumpuan kerukunan dan perdamaian namun seringkali menjadi salah satu sumber konflik dan dianggap sebagai pendorong munculnya perpecahan. Kepentingan politik, tekanan kekuasaan, pergolakan budaya, dan ketidakpastian sosial membuat agama disalahgunakan sehingga menimbulkan perpecahan.

Menurut Kashima, agama menjadi salah satu sumber budaya kontemporer pemicu konflik antar kelompok di seluruh dunia (Kashima, 2015). Pengamat politik dan ekonomi menyatakan bahwa keragaman agama cenderung mendorong ketidaktoleranan beragama dan lebih rentan memicu konflik (Dowd, 2014; Easterly \& Levine, 1997; Esteban \& Mayoral, 2011; Karatnicky, 2002; Lipset, 1959; Montalvo \& Reynal-Querol, 2003).

Pada konteks agama, konflik dapat dipicu karena ketidaksesuaian konsepsi, ide, persepsi ataupun implementasi ajaran agama yang telah ditetapkan oleh syariat agama (Yunus, 2014). Lebih lanjut, Yunus mengungkapkan bahwa klaim kebenaran menjadi salah satu faktor penyebab konflik antar umat beragama. Faktor klaim kebenaran terjadi karena umat beragama cenderung berusaha membenarkan keyakinan agamanya masing-masing, walaupun dalam kenyataannya mereka belum sepenuhnya memahami nilai-nilai esensial dari agamanya. Mereka menganggap telah mengerti, mempunyai, bahkan menerapkan nilai-nilai suci secara murni. Anggapan seperti kelompok lain di luar kelompok mereka sebagai the other, terbentuk karena mereka sudah terperangkap pada koloni dogma masing-masing yang akan selalu melahirkan sikap fanatisme. Akibatnya, timbul pemaksaan pemahamaan ajaran kepada orang lain yang berbeda paham dan keyakinan dengan mereka, bahkan tidak dapat dipungkiri justifikasi bahwa agamanya-lah yang paling benar dapat terjadi.

Ada dua agama yang mayoritas dianut oleh penduduk di Indonesia yaitu Islam dan Kristen. Pusat teologi dalam Islam meliputi tauhid atau keesaan Allah Yang Maha Kuasa, hal ini dianggap sebagai tatanan iman yang paling tinggi dari keyakinan Islam, dimana Allah adalah satu dan satu-satunya Tuhan (Manus, Ilongo, \& Makhalemele, 2016). Sedangkan dalam agama Kristen, Yesus merupakan tokoh sentral yang menjadi panutan dan Juru Selamat umat-Nya. Yesus mengatakan kepada para pengikut mereka untuk melihat kehidupan-Nya sebagai model representasi untuk memahami kehidupan, karakter, dan ajaran agama (Harris, 2007).

Fenomena gesekan konflik diantaranya terjadi pada bulan Februari tahun 2018, dimana pada saat itu beredar surat dari Persekutuan Gereja-gereja Kabupaten Jayapura (PPGJ) yang berisi aspirasi atas keresahan umat kristiani di Jayapura. Dalam surat edaran tersebut memuat beberapa poin yang telah disetujui oleh 25 pendeta di Jayapura. Poinpoin tersebut diantaranya adalah bunyi azan harus diarahkan ke dalam masjid dan tidak kepada khalayak umum, tidak boleh berdakwah di tanah Papua (secara khusus di kabupaten Jayapura), siswa sekolah negeri tidak boleh menggunakan pakaian bernuansa agama tertentu, tidak boleh ada ruang khusus seperti mushala pada fasilitas umum, area perumahan KPR BTN tidak boleh ada pembangunan masjid dan mushala, tinggi bangunan rumah ibadah agama lain tidak boleh melebihi tinggi bangunan gedung gereja yang ada disekitarnya, dan pembangunan rumah ibadah di Kabupaten Jayapura harus mendapatkan rekomendasi bersama PGGJ, pemerintah daerah dan pemilik hak ulayat sesuai dengan peraturan pemerintah (Intan dan Yulianto, 2018). (Scobie \& Scobie, 1998)

Berbagai konflik yang pernah dan mungkin tengah terjadi memberikan dampak yang dirasakan oleh banyak pihak. Untuk menghindari konsekuensi yang akan merugikan baik secara materiil, fisik, dan psikologis, maka diperlukan adanya suatu strategi yang 
konstruktif. Salah satu cara konstruktif untuk meghindari konsekuensi yang demikian adalah dengan melakukan forgiveness (Scobie \& Scobie, 1998).

Forgiveness merupakan satu pilihan yang dapat dilakukan seseorang atau kelompok dalam menangani situasi masa lalu yang melibatkan pelecehan, rasa sakit, kehilangan, dan kematian (Chang, Yeh, \& Hsu, 2016). Enrigth mendefinisikan forgiveness sebagai proses yang kompleks untuk mengganti pemikiran, aksi, dan perasaan yang negatif ke arah yang lebih positif (Enright \& Fitzgibbons, 2000). McCullough dan rekanrekan mengusulkan definisi dari forgiveness yaitu pengalihan motivasi dari negatif ke positif terhadap pihak yang menyakiti yaitu dengan cara menurunkan motivasi untuk menghindar dan menurunkan motivasi untuk membalas dendam (McCullough, Fincham, \& Tsang, 2003). Definisi ini meletakkan motivasi sebagai fokus dari forgiveness dan memandang sebagai transisi prososial antar pribadi, sehingga dapat disimpulkan forgiveness adalah proses interpersonal mengenai hubungan interpersonal.

Agama tumbuh dari kebutuhan untuk memahami atau menemukan sesuatu yang perlu dipahami dalam masalah eksistensial yang dihadapi manusia (Baumeister, 1991; Kotarba, 1983). Pargament menyatakan alasan agama berperan dalam forgiveness adalah karena agama memberikan makna spiritual pada tindakan memaafkan dan agama memberikan panutan serta cara yang konkret untuk memudahkan dalam memberi maaf (Emmons, 2005).

Tsang, McCullough, dan Hoyt (2005) mencatat bahwa secara tidak langsung, religiusitas berpotensi memunculkan sikap memaafkan, karena pada prinsip dasarnya setiap agama mengajarkan untuk saling mencintai dan mengasihi. Forgiveness dianggap konsep religius dalam agama dan budaya (McCullough, Bono, \& Root, 2005). Pemahaman mengenai rasa bersalah, melakukan rekonsiliasi, mendapatkan keselamatan, dan melakukan penebusan adalah hal umum bagi banyak agama (Park, 2005). Forgiveness memiliki peran yang universal dalam agama dan budaya seperti menjaga stabilitas dalam hubungan manusia di kehidupan sosial dan kehidupan spiritual. Walaupun memiliki peran yang sama dalam setiap agama, namun konsep forgiveness antar agama tetap memiliki perbedaan.

Agama Islam dan Kristen mempunyai pandangan yang berbeda mengenai konsep forgiveness. Agama Islam cenderung menyoroti gagasan mengenai pertobatan dan keadilan, sedangkan agama Kristen lebih menekankan pentingnya belas kasih, cinta, dan memberikan pemaafan tanpa prasyarat (Auerbach, 2005). Penelitian yang dilakukan oleh Mullet dan Azhar mengenai perbedaan forgiveness disposisional pada orang Muslim dan Kristen di Lebanon yang dilihat menggunakan model 3 faktor Eropa Barat (kebencian abadi, kepekaan tehadap keadaan, dan pemaafan tanpa syarat). Hasilnya, pada aspek pemaafan tanpa syarat, partisipan Muslim Lebanon memiliki skor yang lebih rendah dibandingkan dengan partisipan Kristen Lebanon. Pemaafan tanpa syarat tidak boleh ditafsirkan sebagai indikasi kelemahan atau imoralitas dari si pemberi maaf, karena pemaafan tanpa syarat secara teoritis ada dan menjadi prinsip utama dari umat Kristen (Mullet \& Azar, 2009).

Pada ajaran agama Islam, mendapatkan pemaafan dari Allah merupakan fondasi teologikal penting, disamping itu pemaafan interpersonal dihargai oleh Islam terutama karena nilai-nilai pemaafan dari Allah. Islam menghargai pemafaan interpersonal karena dapat memperbaiki hubungan dan memfasilitasi perdamaian (McCullough, Pargament, \& Thoresen, 2000). Berbeda dengan perintah sepihak untuk memaafkan dalam Injil Kristen, perintah Al-Qur'an berakar pada visi keadilan yang membutuhkan timbal balik antara pelaku dan korban. Pelaku diharapkan untuk menunjukkan pertobatan dan penyesalan, dan secara eksplisit, berulang kali memohon maaf dari korbannya (Mullet \& Azar, 2009). Penelitian Azar dan Mullet (2009) juga melihat adanya faktor kebencian abadi (lasting resentment). Faktor ini berisi aitem yang menyatakan kecenderungan pihak korban untuk mengekspresikan emosi negatif, kognisi negatif, dan menunjukkan perilaku penghindaran 
terhadap pelaku. Konsep ini hampir serupa dengan konsep avoidance (penghindaran terhadap pelaku) yang dikemukakan oleh McCullough. Hasil dari penelitian ini menunjukkan bahwa pemaafan dari orang Muslim erat kaitannya dengan pengurangan kebencian dari pihak korban. Tindakan atau perilaku meminta maaf dari pelaku merupakan kondisi yang diperlukan agar kebencian dari pihak korban melemah dan agar pelaku mendapatkan pemaafan dari pihak korban (Mullet \& Azar, 2009).

Bugay dan Mullet juga melakukan penelitian yang sama pada mahasiswa Turki dan Perancis yang juga melihat faktor kebencian abadi, faktor kepekaan terhadap keadaan, dan faktor pemaafan tanpa syarat. Hasilnya, partisipan Turki, yang berlatar belakang Islam, cenderung mengkonseptualisasikan pemaafan sebagai proses untuk mendorong pertobatan dari pihak yang melanggar. Unconditional forgiveness dan unconditional seeking for forgiveness, pada partisipan Perancis lebih tinggi daripada partisipan Turki. Selanjutnya, hal penting mengenai proses pemaafan yang akan diberikan oleh pihak korban sangat berkaitan dengan permintaan maaf dan pertaubatan dari pihak pelaku (Bugay \& Mullet, 2013).

Berbeda dengan komunitas Muslim, pada komunitas Kristen dipahami bahwa forgiveness diberikan sebagai keharusan moral, tanpa banyak pertimbangan (Rye dkk., 2000). Umat Kristen menetapkan bahwa forgiveness merupakan inti dari ajaran mereka, dimana pemaafan harus diberikan tanpa syarat kepada teman dan musuh, terlepas dari besarnya kejahatan atau perilaku pelaku. Gagasan pemaafan tanpa batas itu terkait dalam tradisi Kristen mengenai gagasan tentang dosa waris, dimana semua manusia dikandung dalam dosa dan karena itu ditakdirkan untuk hidup berdosa, mereka berhak atas pemaafan Schimmel dalam (Auerbach, 2005).

Penelitian yang dilakukan oleh Kim dan Enright (2014), Benson (dalam McCullough dan Worthington, 1994) mengidentifikasikan bahwa ada sejumlah tahapan seseorang dapat memaafkan dalam perspektif agama Kristen. Tahap pertama, pihak korban akan mengidentifikasi kebencian dan kemarahan yang dirasakan sehubungan dengan tindakan pelanggaran yang telah dilakukan. Tahap kedua, pihak korban mengidentifikasi kesalahan yang telah pelaku lakukan untuk mendapatkan belas kasih. Tahap ketiga, pihak korban akan menyadari bahwa Yesus pasti memberikan maaf kepada pelaku, dan tahap keempat, pihak korban akan mengadopsi kesediaan Yesus untuk memberikan maaf kepada pelaku dan kemudian membangun hubungan baik dengan pelaku (Kim \& Enright, 2014; McCullough \& Wothington, 1994).

Pemaafan dalam perspektif agama berfungsi sebagai sistem yang relevan dalam memberikan makna pada tindakan pemaafan, berpotensi mempengaruhi keyakinan orang, emosi, tindakan, dan tujuan yang berkaitan dengan pemaafan, melalui penekanan agama pada cinta dan kasih sayang yang universal (Tsang, McCullough, \& Hoyt, 2005). Agama juga memiliki sistem makna keadilan yang memungkinkan individu untuk menggunakan agama sebagai rasionalisasi untuk membalas dendam. Hal ini memunculkan pertanyaan yang sangat relevan mengenai apakah agama-agama yang berbeda mempengaruhi sikap pemaafan yang berbeda pula di antara pengikut agama-agama tersebut.

\section{Forgiveness}

Enrigth (2000) mendefinisikan forgiveness sebagai proses yang kompleks antara perilaku, kognisi, dan afeksi. Beliau menjelaskan bahwa forgiveness merupakan proses mengubah pemikiran, tindakan, dan perasaan yang negatif kearah yang lebih positif. Sedikit berbeda, konsep yang diajukan McCullough dan rekan-rekannya mengenai forgiveness lebih mengarah pada perubahan motivasi. Mereka mendefinisikan forgiveness sebagai perubahan arah motivasi dari yang negatif ke arah yang lebih positif, biasanya juga diiringi dengan motivasi untuk berdamai dengan pelanggar atau pelaku. Penelitian ini menggunakan konsep forgiveness yang dicetuskan oleh McCullough dan rekan-rekan (Enright \& Fitzgibbons, 2000; McCullough dkk., 2003). 
McCullough mengembangkan dua dimensi motivasi dari Skala Forgiveness yang disusun oleh Wade (1989), yaitu avoidance dan revenge. Dua dimensi motivasi tersebut dapat melihat aspek-aspek yang berbeda dari motivasi interpersonal individu mengenai hal yang membuat individu terluka dan pelaku atau pihak yang membuatnya terluka. Avoidance motivation (perilaku menghindar) merupakan respon atau motivasi untuk menghindari kontak pribadi maupun kontak psikis dengan pelaku akibat dari luka yang dirasakan dan revenge motivation (balas dendam) merupakan perasaan kemarahan seiring dengan motivasi untuk membalas dendam atau melihat bahaya yang menimpa ke pelaku (McCullough \& Worthington, 1999).

Forgiveness dapat dinilai dari tingkat motivasi negatif yang ditampilkan pihak korban terhadap pelaku. Dua motivasi yang berbeda ini secara bersama-sama menciptakan keadaan psikologis yang disebut sebagai forgiveness (pemaafan). Ketika seseorang memaafkan, mereka mewujudkan hubungan yang konstruktif, dilihat dengan rendahnya motivasi untuk menghindari pelaku dan rendahnya motivasi untuk membalas dendam kepada pelaku (McCullough \& Worthington, 1999). Berbeda dengan pihak korban yang belum bisa memaafkan tindakan menyakitkan dari pelaku, korban akan memiliki motivasi tinggi untuk menghindari kontak dengan pelaku (avoidance) dan memiliki motivasi tinggi untuk membalas dendam atau melakukan sesuatu hal buruk kepada pelaku (revenge).

\section{Agama}

Menurut Baumeister (1991), agama adalah sumber nilai yang sangat kuat bagi individu maupun untuk seluruh budaya (Park, 2005). Agama menggambarkan ritual (upacara) yang dilakukan karena percaya kepada kekuatan adikodrati (Marzali, 2016). Pada tiap-tiap agama yang ada memiliki tiga elemen dasar, yaitu benda-benda sakral, seperangkat keyakinan dan praktik, dan keberadaan komunitas (Durkheim dalam Landmann, 2013). Agama memiliki konsep untuk menentukan apa yang baik dan benar yang harus dicari dan untuk menentukkan apa yang buruk dan salah yang harus dihindari. Kehendak Tuhan dapat dianggap sebagai pengadil utama tentang benar dan salah, oleh karena itu agama berada dalam posisi yang sangat agung untuk dapat menentukan atau menetapkan kriteria tentang benar, salah, baik, dan buruk, agama juga menjadi sumber nilai yang paling kuat di banyak kebudayaan (Baumeister, 1991; Emmons, 1999 dalam Park, 2005).

Baumeister menulis bahwa agama merupakan seperangkat doktrin tentang realitas sehari-hari dan supernatural yang memungkinkan orang untuk memahami konteksnya secara lebih luas dan fundamental. Agama menjamin bahwa apa pun yang terjadi pada individu, tidak peduli seberapa baik atau buruknya, akan masuk akal. Dengan demikian, agama memiliki konsep untuk mengerti, memahami dan mengevaluasi peristiwa sehari-hari (Park, 2005).

\section{Agama Islam}

Salima adalah akar kata Islam yang berarti selamat. Dari kata itu terbentuk aslama yang artinya menyerahkan diri atau tunduk dan patuh, kata inilah yang membentuk kata Islam (Jamal, 2011). Secara istilah dapat dikatakan Islam adalah agama wahyu. Islam merupakan agama Allah SWT yang diturunkan kepada Nabi Muhammad SAW sebagai utusan-Nya yang terakhir, ajarannya meliputi seluruh aspek kehidupan yang berlaku bagi seluruh umat manusia dari generasi ke generasi. Fokus teologi dalam Islam meliputi tauhid atau keesaan Allah Yang Maha Kuasa, hal ini dianggap sebagai tatanan iman yang paling tinggi dari keyakinan Islam, dimana Allah adalah satu dan satu-satunya Tuhan (Manus dkk., 2016).

Seseorang dinyatakan telah masuk sebagai orang Islam dengan membaca kalimat Syahadat yang merupakan pengakuan iman Muslim (yaitu saksi dari Keesaan Allah SWT 
dan Nabi Muhammad SAW sebagai utusan Allah SWT) dan memiliki iman untuk memenuhi semua tugas agama dan mematuhi semua perintah dari Allah SWT. Muslim adalah sebutan untuk pemeluk agama Islam yang berarti orang-orang yang memeluk Islam berarti menyerahkan diri kepada Allah dan siap patuh pada ajaran-Nya. Keyakinan agama di dalam Islam di satu sisi, meliputi keyakinan yang tak perlu dipertanyakan lagi akan keberadaan Allah dan di sisi lain keyakinan dalam Al-Qur'an sebagai sabda murni Allah (Ruthven, 2000 dalam (El-Menouar, 2014). Ritual utama keagamaan dalam Islam seperti yang dijelaskan dalam lima rukun Islam adalah syarat utama yang harus dijalankan oleh umat Islam di seluruh dunia.

\section{Agama Kristen}

Agama Kristen dimulai sebagai suatu gerakan dalam agama Yahudi selama abad pertama (berasal dari masa kelahiran Yesus). Pada saat itu, rabi Yahudi yang sekarang dikenal sebagai Yesus dari Nazaret melakukan pelayanan pengajaran umum di mana dia berkhotbah tentang kedatangan Kerajaan Allah yang akan segera terjadi. Seperti yang dilaporkan dalam Kitab Suci Kristen (umumnya dikenal di kalangan orang Kristen sebagai Perjanjian Baru), Yesus mengumpulkan kelompok inti dari dua belas murid Yahudi, bersama dengan banyak pengikut lainnya. Bersama-sama mereka melayani orang miskin dan terbuang di Israel dan Palestina. Sekitar tahun 33, Yesus ditangkap dan dieksekusi oleh pemimpin Romawi. Namun, para pengikut Yesus mengklaim bahwa Yesus bangkit dari kematian, mereka menjadi percaya bahwa Yesus adalah Anak Allah. Kematian dan kebangkitan Yesus menyelamatkan mereka dari dosa-dosa mereka (Harris, 2007).

Keyakinan mereka terhadap Yesus bertumbuh, mereka menamai Yesus sebagai "Kristus", yang berarti Mesias atau Yang Diurapi (menurut nubuat-nubuat Alkitab Yahudi dan Kitab-Kitab Ibrani). Ini adalah asal muasal nama "Yesus Kristus" dan menyebabkan pengikut Yesus disebut "Kristen." Dalam agama Kristen, Yesus merupakan tokoh sentral yang menjadi panutan umatnya. Yesus mengatakan kepada para pengikut mereka untuk melihat kehidupan mereka sebagai model representasi untuk memahami kehidupan, karakter, dan ajaran agama (Harris, 2007). Keyakinan orang Kristen tentang Yesus didasarkan pada kitab suci, artefak, dan dokumen bersejarah lainnya. Karena beberapa dari dokumen-dokumen ini mengandung informasi tentang Yesus, sebagian besar pengetahuan berasal dari Kitab Suci Kristen.

\section{Metode Penelitian}

\section{Rancangan penelitian}

Penelitian ini menggunakan pendekatan kuantitatif komparatif dimana peneliti membandingkan dua kelompok subyek yang berbeda (Muhid, 2019).

\section{Subyek penelitian}

Subyek penelitian adalah mahasiswa di Indonesia dengan latar belakang pendidikan sebagai mahasiswa (D3 hingga S3) yang memeluk agama Islam dan agama Kristen. Proses penyebaran skala penelitian dilakukan secara online. Mayoritas subyek penelitian memiliki latar belakang pendidikan S1 dan D4. Dari Dari hasil penyebaran skala, diperoleh sejumlah 1.497 mahasiswa, dengan rincian sebanyak 1.003 sampel beragama Islam dan sebanyak 494 sampel beragama Kristen yang berasal dari perguruan tinggi di Indonesia.

\section{Instrumen}

Skala yang digunakan dalam penelitian ini adalah skala forgiveness yang telah diadaptasi dari skala Transgression-Related Interpersonal Motivation (TRIM) 12 McCollough (1998). Skala Transgression-Related Interpersonal Motivation (TRIM) 12 
memiliki 12 aitem dengan dua dimensi yaitu avoidance motivation (motivasi untuk menghindar) dan revenge motivation (motivasi untuk balas dendam). TRIM-12 terdiri dari 12 item pernyataan yang terbagi menjadi dua sub-skala yaitu 7 item untuk avoidance motivation bertujuan mengukur motivasi individu agar dapat menghindari individu yang telah menyakiti dan 5 item untuk revenge motivation untuk mengukur individu membalaskan dendam kepada individu yang telah menyakiti.

Skala ini digunakan untuk mengukur tingkat forgiveness dari subjek, apabila semakin tinggi perolehan skor rata-rata setiap dimensi berarti forgiveness rendah, sebaliknya apabila semakin rendah perolehan skor rata-rata setiap dimensi maka forgiveness tinggi. Cara menjawab dalam skala ini dengan memilih alternatif jawaban yang mendekati dengan kondisi diri subjek. Pemberian skor didapat dengan cara menjumlahkan keseluruhan jawaban yang diberikan subjek dari item. Forgiveness dinyatakan tinggi jika individu mampu memaafkan orang lain dalam arti tidak berperilaku membalas dendam atau menghindar.

\section{Hasil Penelitian}

Berdasarkan proses analisis, subyek penelitian pemeluk agama Islam dan pemeluk agama Kristen mayoritas memiliki kategori forgiveness yang berada pada kategori sedang.

Tabel 1

Hasil Uji Beda

\begin{tabular}{ccccc}
\hline Variabel & Statistik & Nilai & Keterangan & Kesimpulan \\
\hline \multirow{2}{*}{ Forgiveness } & $\mathrm{t}$ & -1.680 & & \multirow{2}{*}{ Tidak ada beda } \\
\cline { 2 - 4 } & $\mathrm{p}$-value (Sig) & .093 & p-value $>0.05$ & \\
\hline
\end{tabular}

Dari tabel di atas, dapat dilihat nilai Signifikansi yang didapatkan sebesar 0.093, dimana nilai signifikansi tersebut lebih dari $\alpha .05(0.093>.05)$, sehingga disimpulkan bahwa tidak terdapat perbedaan forgiveness antara pemeluk agama Islam dan pemeluk agama Kristen (Ha ditolak).

\section{Analisis Tambahan}

Peneliti juga melihat perbedaan pada tiap dimensi forgiveness, yaitu dimensi avoidance dan dimensi revenge, dengan membandingkan sampel pemeluk agama Islam dan pemeluk agama Kristen. Berikut adalah hasil uji beda pada tiap dimensi:

Tabel 2

Hasil Uji Beda Dimensi Avoidance

\begin{tabular}{ccccc}
\hline Variabel & Statistik & Nilai & Keterangan & Kesimpulan \\
\hline \multirow{2}{*}{ Avoidance } & $\mathrm{t}$ & -1.778 & & Tidak ada beda \\
\cline { 2 - 4 } & $\mathrm{p}$-value (Sig) & .076 & $\mathrm{p}$-value $>0.05$ & Tidak ada beda \\
\hline Revenge & $\mathrm{t}$ & -1.255 & $\mathrm{p}$-value $>0.05$ & \\
\hline
\end{tabular}

Dari tabel di atas, diperoleh data bahwa nilai signifikansi pada dua dimensi lebih besar dari $\alpha=0.05$, sehingga dapat disimpulkan tidak terdapat perbedaan rerata antara pemeluk agama Islam dengan pemeluk agama Kristen. 


\section{Pembahasan}

Hasil analisis menunjukkan tidak terdapat perbedaan motivasi forgiveness pada mahasiswa pemeluk agama Islam dan pemeluk agama Kristen. Religiusitas, afilasi agama dan keterlibatan dalam kegiatan keagamaan adalah faktor yang berperan dalam forgiveness. Hasil penelitian ini hampir sama dengan penelitian Suchday, Friedberg, dan Almeida (2006) pada siswa di New York yang juga menunjukkan tidak adamya perbedaan paa kesediaan mereka untuk memaafkan. Penelitian Suwartono, Parwasti, dan Mullet (2007) di kalangan pelajar Indonesia juga memberikan hasil yang sama, yaitu tradisi agama dan keterlibatan pada kegiatan agama bukanlah prediktor kesediaan untuk memaafkan. Fu, Watkins, dan Hui (2004) yang menggunakan sampel penelitian dari Republik Rakyat Cina juga tidak menemukan adanya korelasi antara tradisi agama dan keinginan untuk memaafkan (Fu, Watkins, \& Hui, 2004; Suchday, Friedberg, \& Almeida, 2006; Suwartono, Parwasti, \& Mullet, 2007).

Studi lain yang mendukung hasil dalam penelitian ini adalah studi yang dilakukan oleh Azar dan Mullet yang menunjukkan tidak terdapat perbedaan dalam sikap memaafkan responden berdasarkan agama. Orang-orang dari setiap komunitas di Lebanon menyatakan kesediaan untuk memaafkan daripada keinginan untuk membalas dendam. Tinjauan konsep pengampunan dalam agama-agama besar dunia menunjukkan bahwa meskipun berbeda dalam memahami konsepnya, pengampunan tetap ada dalam setiap agama besar dunia. Manusia diharapkan untuk meniru Tuhan yang memiliki sifat memaafkan, selain itu hal ini juga menjadi salah satu motivasi bagi individu untuk saling memaafkan. Jika individu dimaafkan karena kesalahannya maka ia harus belajar memaafkan orang lain, terutama jika individu tersebut juga mencari pemaafan dari Tuhan. Individu yang mampu memaafkan akan diberikan pahala di masa sekarang atau setelah kematian (McCullough dkk., 2000; Mullet \& Azar, 2009)

Agama dapat menjadi alasan mengapa individu bisa menghargai proses memaafkan dan ingin memaafkan orang lain (Kidwell, 2009). Dalam penelitiannya, Kidwell mengatakan bahwa individu menggunakan strategi keagamaan dalam usaha untuk memaafkan orang lain dengan menggunakan agama sebagai sumber motivasi akan lebih mudah untuk bisa memaafkan. Strategi keagamaan disini diantaranya adalah doa, meminta bantuan kepada Tuhan, membaca buku atau teks agama untuk memaafkan pelaku. Pada responden muslim dan Kristen disebtukan bahwa dengan membaca Al-Quran dan Alkitab dapat membantu, membimbing serta menginspirasi individu untuk dapat memaafkan. Agama-agama besar dunia sangat menekankan pada konsep pemaafkan sehingga hal ini membantu individu untuk lebih mudah memaafkan (Worthington, Sandage, \& Berry, 2000). Jika individu memiliki keyakinan agama yang kuat dapat memungkinkan untuk memaafkan, invidividu yang memiliki komitken tinggi pada agama cenderung memaafkan orang lain (Worthington, Kurusu, McCullough, \& Sandage, 1996). Komitmen agama secara signifikan juga mempengaruhi proses pemaafan, oleh karena itu komitmen agama dapat berfungsi sebagai predictor pemaafan yang potensial (McCullough \& Worthington, 1999).

\section{Simpulan dan Saran}

Hasil studi ini menunjukkan bahwa agama menjadi salah satu faktor seseorang untuk cenderung memaafkan. Selain itu tidak ada perbedaan motivasi memaafkan pada mahasiswa pemeluk agama Islam dan mahasiswa pemeluk agama Kristen. Demikian pula pada analisa dimensi yaitu dimensi avoidance dan dimensi revenge juga tidak ditemukan adanya perbedaan. Peneliti yang ingin mengangkat tema ini harus mempertimbangkan bahwa setiap agama memiliki penekanan yang berbeda mengenai konsep forgiveness. 


\section{Daftar Pustaka}

Auerbach, Y. (2005). Forgiveness and reconciliation: The religious dimension. Terrorism and Political Violence, 17, 469-485.

Badan Pusat Statistik Jakarta Pusat. (2010). Statistik Indonesia Tahun 2010. Jakarta Pusat: Badan Pusat Statistik.

Baumeister, R. F. (1991). Meanings of life. New York: The Guilford Press.

Bugay, A., \& Mullet, E. (2013). Conceptualizing forgiveness, granting forgiveness, and seeking forgiveness: A turkish-french comparison. Review of European Studies, 5, 187-196.

Chang, J. H., Yeh, K., \& Hsu, S. (2016). New Dimensions of Forgiveness in Conflict Resolution and Peace Studies. International Journal of Humanities and Social Science Review, 2, 7-12.

Dowd, R. A. (2014). Religious Diversity and Religious Tolerance: Lessons from Nigeria. Journal of Conflict Resolution, 60, 617-644.

Easterly, W. R., \& Levine, R. (1997). Africa's Growth Tragedy: Policies and Ethnic Divisions. The Quarterly Journal of Economics, 4, 69-105.

El-Menouar, Y. (2014). The Five Dimensions of Muslim Religiosity: Result of An Empirical Study. Methods, Data, Analysis, 8, 53-78.

Emmons, R. A. (2005). Emotion and religion. Dalam R. F. Paloutzian \& C. L. Park (Eds.), Handbook of the Psychology of Religion and Spirituality. New York: Guilford Press.

Enright, R. D., \& Fitzgibbons, R. P. (2000). Helping Clients Forgive: An Empirical Guide for Resolving Anger and Restoring Hope. Washington, DC: American Psychological Association.

Esteban, J., \& Mayoral, L. (2011). Ethnic and Religious Polarization and Social Conflict. UFAE and IAE Working Papers. Chicago: University of Chicago Press.

Fu, H., Watkins, D., \& Hui, E. K. P. (2004). Personality Correlates of The Disposition Towards Interpersonal Forgiveness: A Chinese Perspective. International Journal of Psychology, 39, 305-316.

Harris, R. T. (2007). Islam and Christianity: A Comparative Missiological Analysis [Tesis]. South African Theological Seminary.

Jamal, M. (2011). Konsep Al-Islam dalam Al-quran. Jurnal Al-Ulum, 11, 283-310.

Karatnicky, A. (2002). The 2001 Freedom House Survey: Muslims Countries and The Democracy Gap. Journal of Democracy, 13, 99-112.

Kashima, Y. (2015). Culture and Psychology in the 21st Century: Conceptions of Culture and Person for Psychology Revisited. Journal of Cross-Cultural Psychology, 47, 4-20.

Kidwell, J. E. M. (2009). Exploring the Relationship Between Religious Commitment and Forgiveness Through Quantitative and Qualitative Study (hlm. 1-146) [ProQuest Dissertations and Theses].

Kim, J., \& Enright, R. D. (2014). Differing Views on Forgiveness Within Christianity: Do Graduate-Level Theology Students Perceive Divine and Human Forgiveness Differently. Spirituality in Clinical Practice, 1, 191-202.

Kotarba, J. A. (1983). Perceptions of Death, Belief Systems and The Process of Coping with Chronic Pain. Social Science and Medicine, 17, 681-689.

Landmann, A. (2013). The Study of Religion-Thoughts on Approaches. Journal of Religious Culture, 177, 1-12.

Lipset, S. M. (1959). Some Social Requisites for Democracy: Economic Development and Political Legitimacy. American Political Science Review, 53, 69-105.

Manus, C. U., Ilongo, F. N., \& Makhalemele, N. T. (2016). A Comparative Study of Christianity and Islam In The Contemporary Basotho Society. International Journal of Science and Research (IJSR), 5, 138-146. 
Marzali, A. (2016). Agama dan Kebudayaan. UMBARA: Indonesian Journal of Anthropology, $1,57-75$.

McCullough, M. E., Bono, G., \& Root, L. M. (2005). Religion and forgiveness. Dalam R. F. Paloutzian \& C. L. Park (Eds.) Handbook of The Psychology of Religion and Spirituality. New York: Guilford Press.

McCullough, M. E., Fincham, F. D., \& Tsang, J. (2003). Forgiveness, Forbearance, and Time: The Temporal Unfolding of Transgression-Related Interpersonal Motivations. Journal of Personality and Social Psychology, 84, 540-557.

McCullough, M. E., Pargament, K. I., \& Thoresen, C. E. (2000). Forgiveness theory research and practice. New York: Guilford Press.

McCullough, M. E., \& Worthington, Jr. (1999). Religion and Forgiving Personality. Journal of Personality, 67, 1141-1164.

McCullough, M. E., \& Wothington, Jr. (1994). Models of Interpersonal Forgiveness and Their Applications to Counseling: Review and Critique. Counseling and Values, 39, 2-14.

Montalvo, J., \& Reynal-Querol, M. (2003). Religious Polarization and Economic Development. Economic Letters, 80, 201-210.

Muhid, A. (2019). Analisis Statistik: 5 Langkah Praktis Analisis Statistik dengan SPSS for Windows (2 ed.). Sidoarjo: Zilfatama Jawara.

Mullet, E., \& Azar, F. (2009). Apologies, Repentance, and Forgiveness: A Muslim-Christian Comparison. The International Journal for the Psychology of Religion, 16, 275-285.

Park, C. L. (2005). Religion and meaning. Dalam R. F. Paloutzian \& C. L. Park (Eds.), Handbook of The Psychology of Religion and Spirituality. New York: Guilford Press.

Rye, M. S., Pargament, K. I., Ali, M. A., Beck, G. L., Dorff, E. N., \& Hallisey, C. (2000). Religious Perspectives on Forgiveness. Dalam M. E. McCullough, K. I. Pargament \& C. E. Thoresen (Eds.), Forgiveness: Theory, Research, and Practice. New York: Guilford Press.

Scobie, G. E. W., \& Scobie, E. D. (1998). Accessing the Forgiveness Construct. Archive for The Psychology of Religion, 23, 295-311.

Suchday, S., Friedberg, J. P., \& Almeida, M. (2006). Forgiveness and Rumination: A CrossCultural Perspective Comparing India and the US. Stress and Health, 22, 81-89.

Suwartono, C., Parwasti, Y., \& Mullet, E. (2007). Effect of Culture on Forgivingness: A Southern Asia-Western Europe Comparison. Journal of Personality and Individual Differences, 42, 513-523.

Tsang, J., McCullough, M. E., \& Hoyt, W. T. (2005). Psychometric and Rationalization Accounts of the Religion-Forgiveness Discrepancy. Journal of Social Issues, 61, 785805.

Worthington, Jr., Kurusu, T. A., McCullough, M. E., \& Sandage, S. (1996). Empirical Research on Religion and Psychotherapeutic Processes and Outcomes: A 10-Year Review and Research Prospectus. Psychological Bulletin, 119, 448-487.

Worthington, Jr., Sandage, S. J., \& Berry, J. W. (2000). Group interventions to promote forgiveness: What researchers and clinicians ought to know. Dalam M. E. McCullough, K. I. Pargament, \& C. Thoresen (Eds.), Forgiveness: Theory, research, and practice. New York: Guilford Press.

Yunus, F. M. (2014). Konflik Agama di Indonesia Problem dan Solusi Pemecahannya. Substantia, 16, 217-228. 